\title{
Nutrition for elderly individuals during the COVID-19 pandemic
}

\author{
Naomi Nakayama ${ }^{1}$
}

Faculty of Health and Nutrition, The University of Shimane, Shimane, Japan

Received $14^{\text {th }}$ August 2019,

Accepted $19^{\text {th }}$ August 2019

Link to DOI:

10.25220/WNJ.V04.i1.0001

Journal Website:

www.worldnutrijournal.org

\section{Introduction}

As Japan has been facing an increasingly aged society ahead of the rest of the world, much interest has been focused on interventions for treating frailty and sarcopenia to extend healthy life expectancy in recent years. The COVID-19 pandemic has led to a crisis in healthcare systems all over the world. It has had a huge impact on not only public health but also the global economy. Due to the lack of effective vaccination and pharmacological antiviral intervention, pandemic control is dependent on public health measures. These measures have basically aimed to decrease social activities and face-to-face communication, including the restriction of public gatherings and compulsory stayat-home policies. ${ }^{1}$ Even though these strategies are effective in controlling the pandemic, social and economic influences have obviously affected vulnerable groups of people, including elderly individuals. Therefore, it is important to enhance the effectiveness of pandemic control measures while

\footnotetext{
Corresponding author:

Nakayama Naomi, MD, PhD

Faculty of Health and Nutrition

The University of Shimane

Shimane, Japan
}

Email address: kennaonatsuno@yahoo.co.jp minimizing secondary negative consequences. This article aimed to describe the importance of maintaining good nutritional and mental health for elderly individuals during the COVID-19 pandemic, with a particular focus on frailty management.

\section{Elderly individuals are vulnerable during in the COVID-19 pandemic}

Several studies support an age gradient in the severity and mortality of COVID-19. ${ }^{2-8}$ It is known that human immunity is supported by nutritional status. In this regard, the immune strength of malnourished and sarcopenic individuals against bacterial and viral infections is lower. In general, elderly individuals tend to have multiple comorbidities, altered body composition (such as sarcopenia), decreased swallowing and ingesting ability, and decreased cognitive function. Moreover, they are disadvantaged socioeconomically. In fact, the rates of severe disease were significantly different depending on the age group. ${ }^{9}$ Furthermore, mortality was also higher in the older age groups, and comorbidities, such as hypertension, diabetes, cardiovascular disease, chronic respiratory disease, and cancer, were associated with an increased risk of death. ${ }^{2}$ In this regard, maintaining good nutritional status as well as preventing infection is important for elderly individuals. 
Nutrition, physical activity, and socialization are important factors for frailty management to enhance physical and mental resilience. However, these three factors are disturbed now because current public health measures can exert unintended adverse secondary effects through a wide range of downstream societal consequences. ${ }^{3}$ The restriction of social activities induces physical frailty, or sarcopenia. Physical distancing increases social isolation and loneliness, leading to depression, cognitive decline, and exacerbations of chronic diseases. ${ }^{10-12}$ A report published by the Japan Dayservice Welfare Association showed that seniors' activities of daily living (ADL) had deteriorated due to reduced operation of healthcare and social services for elderly individuals. ${ }^{13}$ In general, aging is the primary cause of sarcopenia and older adults lose muscle mass as they age. Rates of sarcopenia have accelerated rapidly with restrictions in social activities. Sarcopenic change results in not only decreased ADL but also blood flow stagnation, glucose tolerance, and immune weakness. Taken together, from a nutritional intervention perspective during this COVID-19 pandemic, nutritional care for enhancing immunity to reduce the infection rate and severity and preventing the progression of frailty is important for elderly individuals.

\section{Nutritional care for elderly individuals during the COVID-19 pandemic}

Having a well-balanced diet three times a day regularly is essential for our health. It has been reported that malnutrition can be an independent prognostic factor for influenza infection. ${ }^{14,15}$ The latest food uptake standard issued by the Japan Ministry of Health, Welfare and Labor in 2020 recommended energy intake from protein be increased to $15-20 \%$ for those over 65 years old when considering the nutritional management of sarcopenia. The recommended daily protein intake is $1.2-1.5 \mathrm{~g} / \mathrm{kg}$ body weight. As elderly individuals are generally resistant to muscle anabolism, they need to consume good-quality proteins containing branched-chain amino acids (BCAAs). BCAAs play an important role in muscle synthesis to repress protein degradation and activate protein synthesis. BCAAs are also reported to have roles in gut health, immune function, and insulin sensitivity. ${ }^{16-18}$ Tuna, bonito, poultry, beef, egg, beans, and milk are all rich in BCAAs. Recently, among BCAAs, leucine and $\beta$-hydroxy- $\beta$-methylbutyrate (HMB, its metabolite) have attracted attention for the effective synthesis of muscle proteins [19]. Vitamins and trace elements tend to run short when a balanced diet is destroyed, and their deficiency hinders immune function. It has been reported that vitamin D deficiency is related to the development of infectious diseases, such as influenza infection, human immunodeficiency virus infection, and hepatitis $\mathrm{C}$ virus hepatitis. ${ }^{20,21} \mathrm{We}$ presume that intake of a sufficient amount of vitamin D plays a role in preventing COVID-19 infection, since vitamin $\mathrm{D}$ deficiency is common among elderly individuals. ${ }^{22,23}$ Vitamin A may also play a role in protecting from infection and is considered to be important among pediatric infectious diseases. ${ }^{24}$ Other vitamins, such as E, B6, B12, selenium, and zinc, are also related to immune function, and zinc deficiency has been shown to increase susceptibility to various pathogens. ${ }^{25}$

Probiotics are beneficial in promoting a healthy gut and immune system. ${ }^{26}$ Probiotics can be found in cultured dairy products and fermented products. Vitamin D is naturally found in fatty fish, such as salmon and tuna, and in small amounts in dairy products, egg yolks, and mushrooms. Vitamin A can be found in many fruits and vegetables, such as carrots, sweet potatoes, tomatoes, broccoli, spinach, mango, and peppers.

Adding seafood, fruits, vegetables, dairy products, and beans into the diets of elderly individuals will ensure adequate intake of these immune-boosting minerals.

In addition to the nutritional care described above, in order to avoid losing appetite, routine exercise is important for elderly individuals. In terms of frailty management, enriching the lives of elderly individuals with proper exercise and social relationships should be taken into consideration. Incorporating information and communications technology and social networking services may play a role in these achievements as communication tools and should be promoted positively among older adults during the COVID-19 pandemic. 


\section{Conclusion}

The COVID-19 pandemic has led to the declaration of a state of emergency for the first time in Japan. We have been seized with fear under the strict restriction of our daily lives for pandemic control. I have summarized the requisite nutritional care to preserve the physical resilience of elderly individuals, which also aims to manage frailty.

Elderly individuals should be encouraged to have a healthy and active lifestyle during this pandemic.

\section{Conflict of Interest}

Authors declared no conflict of interest regarding this study.

\section{Open Access}

This article is distributed under the terms of the Creative Commons Attribution 4.0 International Licence (http://creativecommons.org/licenses/by/4.0/), which permits unrestricted use, distribution, and reproduction in any medium, provided you give appropriate credit to the original author(s) and the source, provide a link to the Creative Commons license, and indicate if changes were made.

\section{References}

1. Hartley DM, Perencevich EN. Public Health Interventions for COVID-19: Emerging Evidence and Implications for an Evolving Public Health Crisis. JAMA. 2020. doi: 10.1001/jama.2020.5910

2. $\mathrm{Wu} \mathrm{Z}$, McGoogan JM. Characteristics of and Important lessons from the Coronavirus Disease2019 (COVID-19) outbreak in China: Summary of a report of 72314 cases from the Chinese Center Disease Control and Prevention. JAMA. 2020; 323: 12391242

3. Le Couteur DG, Anderson RM, Newman AB. COVID-19 is a disease of older people. $J$ Gerontol A Biol Sci Med Sci. 2020. doi: 10.1093/gerona/glaa077

4. Zhu N, Zhang D, Wang W, et al. A novel coronavirus from patients with pneumonia in China, 2019. N Engl J Med. 2020; 382: 727-33.

5. Huang $\mathrm{C}$, Wang Y, Li X, et al. Clinical features of patients infected with 2019 novel coronavirus in Wuhan, China: a descriptive study. Lancet. 2020; 395: 497-500.
6. Zhou F, Yu T, Du R, et al. Clinical course and risk factors for mortality of adult inpatients with COVID19 in Wuhan, China: a retrospective cohort study. Lancet. 2020. Mar 11. Doi: 10.1016/S01406736(20)30566-3.

7. Bouadma L, Lescure FX, Lucet JC, et al. Severe SARS-CoV-2 infections: practical considerations and management strategy for intensivists. Intensive Care Med. 2020. Feb 26. Doi: 10.1007/S00134-02005967-x.

8. Chen N, Zhou M, Dong X, et al. Epidemiological and clinical characteristics of 99 cases of 2019 novel coronavirus pneumonia in Wuhan, China: a descriptive study. Lancet. 2020; 395: 507-513.

9. Niu S, Tian S, Lou J, et al. Clinical Characteristics of Older Patients Infected with COVID-19: A Descriptive Study. Arch Gerontol Geriatr. 2020; 89: 104058

10. Chan A, Malhotra C, Malhotra R, Ostbye T. Living arrangements, social networks and depressive symptoms among older men and women in Singapore. Int J Geriatr Psychiatry. 2011; 26: 630639.

11. Valtorta NK, Kanaan M, Gilbody S, Ronzi S, Hanratty B. Loneliness and social isolation as risk factors for coronary heart disease and stroke: systematic review and meta-analysis of longitudinal observational studies. Heart 2016; 102: 1009-1016

12. Zhong BL, Chen SL, Conwell Y. Effects of transient versus chronic loneliness on cognitive function in older adults: Findings from the Chinese longitudinal healthy longevity survey. Am J Geriatr Psychiat 2016; 24: 389-98

13. http://japandayservice.com/pdfs/20200722_01.pdf. Report from Japan Day-service welfare association.

14. Maruyama T, Fujisawa T, Suga S, et al. Outcomes and prognostic features of patients with Influenza requiring hospitalization and receiving early antiviral therapy : A Prospective Multicenter Cohort Study. Chest. 2016; 149: 526-534.

15. Reyes L, Arvelo W, Estevez A, et al. Populationbased surveillance for 2009 pandemic influenza A (H1N1) virus in Guatemala, 2009. Influenza Other Respir. Viruses. 2010; 4: 129-140

16. Nicholas P, Gannon JK, et al. BCAA metabolism and insulin sensitivity-Dysregulated by metabolism status? Mol. Nutr. Food. Res. 2018; 62: 1700756

17. Zang S, Zeng X, Ren M, et al. Novel metabolic and physiological functions of branched chain amino acids: a review. Journal of animal science and biotechnology. 2017, 8:10

18. Nie C, He T, Zhang W, et al. Branched chain amino acids: beyond nutrition metabolism. Int. J. Mol. Sci. 2018; 19: 954 
19. Alfonso J, et al. Beta-Hydroxy-Beta-Methyl Butyrate (HMB): From Experimental Data to Clinical Evidence in Sarcopenia. Curr Protein Pept Sci. 2018;19:668-672

20. Goncalves-Mendes N, Talvas J, Dual C, et al. Impact of vitamin D supplementation on influenza vaccine response and immune function in deficient elderly persons A randomized placebo-controlled trial. Front Immunol 2019; 10: 65.

21. Villar LM, Del Campo JA, Ranchal I, et al: Association between vitamin $\mathrm{D}$ and hepatitis $\mathrm{C}$ virus infection: a meta-analysis. World J Gastroenterol. 2013; 19: 5917-5924,

22. Alexander GC, Qato DM. Ensuring Access to Medications in the US During the COVID-19
Pandemic.

JAMA

2020.

doi:

10.1001/jama.2020.6016

23.https://www.jpngeriatsoc.or.jp/citizen/pdf/for_short stay.pdf. Infection disease prevention in nursing homes Report from Japan Geriatrics Society.

24. West CE, Sijtsma SR, Kouwenhoven B, et al. Epithekia-damaging virus infections affect vitamin A status in chickens. J Nutr. 1992; 122: 333-9.

25. Semba RD, Tang AM. Micronutrients and the pathogenesis of human immunodeficiency virus infection. Br J Nutr. 1999; 81: 181-189.

26. Wilkins T, Sequoia J. Probiotics for gastrointestinal conditions: A summary of the evidence. Am Fam Physician. 2017; 96: 170-8. 